\title{
Public Health and Youth Health Risk Behavior in Central Asia
}

\author{
Liza Rybina, Vladimir Garkavenko \\ Department of Management and Marketing, KIMEP University, Kazakhstan
}

Correspondence Author: Liza Rybina, Department of Management and Marketing, KIMEP University, Kazakhstan

Received date: 23 October 2018, Accepted date: 15 November 2018, Online date: 25 December 2018

Copyright: (C) 2018 Liza Rybina, et al. This is an open-access article distributed under the terms of the Creative Commons Attribution License, which permits unrestricted use, distribution, and reproduction in any medium, provided the original author and source are credited.

\begin{abstract}
The developing economies of Central Asia have been facing challenges in public health with health indicators lagging far behind the economic growth. The study aims to explore youth health risk behaviors. As young people are often underestimate health risk consequences, the main purpose of this research is to explore and compare the perceptions of health risks among youth and experts in public health in the context of Central Asia. The phenomenological research was used to analyze qualitative data from thirteen in-depth interviews with experts from public health, government, and youth organizations and two focus groups with youth. The results of both in-depth interviews with experts and focus groups with youth pointed out negative consequences of health risk behaviors including addictive behaviors such as smoking, alcohol, drugs, gaming. It was established that youth is generally aware of the bad consequences of the health risks, but have a poor understanding of the seriousness and specifics of the health risk. Although health experts have a very good understanding of risks the youth has "imperfect information" about these risks. Recommendations are proposed to prevent or reduce long-term negative consequences of the health risks for individuals and for the whole society.
\end{abstract}

Key words: Health risks, Public health, Youth, Central Asia

\section{INTRODUCTION}

The breakup of the Soviet Union in 1991 put fifteen new countries at the world map. Recently, the five countries of post-Soviet Central Asia (Kazakhstan, Kyrgyzstan, Tajikistan, Turkmenistan and Uzbekistan) celebrated the twenty-fifth anniversary of their independence. The early years of newly founded states hit hard many aspects of the citizens' lives, but overtime the transition from centrally planned socialist system to free-market system brought largely positive fundamental changes and impressive transformations in almost all aspects of political, economic and social spheres. The health systems of Central Asian countries have undergone a profound transition as well [1]. However, the public health systems and health status of the population have been lagging far behind that of the economic growth. According to the European Observatory on Health Systems and Policies, despite of some improvements in the recent years, health indicators have not reached the levels of the late 1980s. The statistics of the World Health Organization $[2,3]$ on Central Asian countries, presented in Table 1 highlight the importance of the research on public health and health promotions to prevent and reduce the major health risks and to improve health of the population as a prerequisite for sustainable socio-economic development of Central Asia countries.

Specifically, the youth behavior is to be researched to develop effective policies on young consumer protection and education [4] and prevent long term negative consequences from the health risks for individuals and for the whole society. As young people are often underestimate health risk consequences, the main purpose of this research is to explore and compare the receptions of health risks among youth and experts in public health in the context of Central Asia.

Table 1: WHO statistics on health expenditures, death rates, and proportional mortality for Noncommunicable Diseases (NCD) 2014

\begin{tabular}{|c|c|c|c|c|c|c|}
\hline \multirow{2}{*}{ Country } & \multirow{2}{*}{$\begin{array}{c}\text { Health expen- } \\
\text { ditures, } \\
\% \text { of GDP }\end{array}$} & \multicolumn{2}{|c|}{$\begin{array}{l}\text { Death rate, crude per } 1000 \\
\text { people }\end{array}$} & \multicolumn{3}{|c|}{$\begin{array}{c}\text { Proportional mortality } \\
\% \text { of total deaths }\end{array}$} \\
\hline & & $\begin{array}{c}\text { Average } \\
\text { 2005-2014 }\end{array}$ & 2014 & NCD & $\begin{array}{c}\text { Cardio-vascular } \\
\text { diseases }\end{array}$ & Cancers \\
\hline Kazakhstan & 4.36 & 9.6 & 8.3 & 84 & 54 & 15 \\
\hline Kyrgyzstan & 6.48 & 7.5 & 6.7 & 80 & 49 & 10 \\
\hline Tajikistan & 6.88 & 7.5 & 6.3 & 62 & 36 & 8 \\
\hline Turkmenistan & 2.08 & 7.4 & 6.2 & 76 & 50 & 9 \\
\hline Uzbekistan & 5.84 & 6.7 & 5.3 & 79 & 54 & 8 \\
\hline
\end{tabular}

\section{Public Health in Central Asia}

The public health as a discipline deals with the health problems that can affect communities, countries, or even the whole world, such as transmitted diseases, provision of medical care, quality and supply of water and food, disability, chronic diseases and other health risks. In broader terms, the focus of public health is to "provide population-based solutions to collectively-defined health problems" [5, p. 15]. Detailed information of the causes on the diseases and health risks is needed to develop efficient interventions and health promotions. The leading causes of death in Central Asian states represent a combination of modern risks such 
Citation: Liza Rybina and Vladimir Garkavenko, 2018. Public Health and Youth Health Risk Behavior in Central Asia. Journal of Applied Sciences Research., 14(6): 1-4. DOI: $10.22587 /$ jasr.2018.14.6.1

as coronary heart disease, stroke, cancers and traditional risks such as pneumonia and other injures [6]. In order to prevent disease and injury, it is important to identify and deal with the health risks that cause them. The situation analysis presented by World Health Statistics provides evidences of the "importance of addressing noncommunicable diseases and their risk factors such as tobacco use, mental health problems, road traffic injuries, and environmental health issues" [3, p. v]. Chronic risks influencing long-term health outcomes are more complex [7]. Each risk has its own causes as well, and thus many risks have rooted in more complex casual chains. Many diseases today are caused by multiple risk factors with roots in smoking and alcohol abuse. Tobacco smoking substantially increases the risks of death from lung and other cancers, stroke, heart disease, chronic respiratory diseases and other conditions [8]. As the only major causes of mortality increasing rapidly today worldwide are HIV, tobacco and overweight $[9,10,11]$, smoking becomes the single largest preventable cause of disease and premature death in the world $[12,13]$ Moreover, at the early age of smoking onset, when growth has not completed, the susceptibility to the damaging effects from smoking is enhanced. The study on prevalence of smoking in eight countries of the former Soviet Union [14] found that the average year of smoking uptake in Kazakhstan is 20.7 among women and 17.6 years old for men. Moreover, about $28 \%$ of male smokers reported that they started to smoke before age 16, almost twice as high as in Kyrgyzstan (14.7\%) but lower than in Russia, Ukraine, and Belarus. As adolescent health is "receiving more attention because of alarming data regarding risk factors such as tobacco use, harmful use of alcohol, HIV incidence and obesity prevalence" [3, p.25], an understanding and description of the all risk factors, causes and their causes, is vital for health decision making and planning of health promotion campaigns targeted at youth to increase health behavior and reduce the impact of health risks in Central Asia.

\section{Materials and Methods}

The qualitative approach was applied in a present study to address the main purpose of this research to explore and compare the perceptions of health risks among youth and experts in public health in the context of Central Asia. A sequential research design was implemented with in-depth interviews with experts followed by youth focus groups. Two sampling strategies were used in interviewing key stakeholders on health risk behavior: maximum variation (width) and critical case (depth). At first, individuals were selected to maximize the variety of perspectives investigated in this research project, including public health, medicine, education, government, and youth organizations. Second, individuals having specific characteristics (education and work experience in related areas) were selected to provide more detailed insights. Thus, combined mixed purposeful sampling approach was employed. Thirteen experts from different areas were selected from preliminary identified organizations to ensure the width (maximum variation representing public health and medicine, government and public administration, education, youth organizations and movements) and depth (personal experience, background, and perspectives of individual experts) of the final sample for in-depth interviews. The unstructured interviews varied in terms of content depending on the areas of expertise of respondents. The audio-recorded interviews were transcribed into text. The texts were analyzed first for the general sense of the information and subsequently analyzed in more details employing coding process [15]. The results of the coding process were used to generate a description of themes for further interpretation and analysis. Thus, the phenomenological research, as recommended by [16], was used to analyze qualitative data to generate meaning units and develop descriptions.

To explore the youth opinions about health risk behaviors, a focus group method was used. Creswell [17] recommends to use the group interview when "the interaction among interviewees will likely yield the best information, when interviewees are similar and cooperative with each other, when time to collect information is limited, and when individuals interviewed one-on-one may be hesitant to provide information" [18, p. 133]. In conducting focus group discussions, an intensity sampling was used. Individuals who had personal experience or were observing health risk behaviors of close people were selected for the study. The target sample sizes for this research were identified using the guidance provided by [18]: 12 participants for the interviews and 10 participants for the focus groups discussion. The homogeneous composition of the focus group in term of age created an open atmosphere where the interaction of the group members stimulated a chain of discussions and brainstorming to list all possible health risk behaviors among youth. Taking into account the possible sensitivity of the issue of health risks behaviors, being in group allowed members to shift the focus from personal to generally discussion, although some participants provided reflections and shared personal experiences. To check the reliability and validity of the materials, two focus groups were administered to verify the results of one group with another. The focus groups were formed according to basic recommendations. Twenty five potential candidates were prescreened and invited to participate in two focus groups. However, only ten appeared for the first and nine for the second focus group discussion session. The semi-structured guide based on the research questions for this study was used in the interviewing process. Upon completion of the focus group interviewing, the audio records data were transcribed into text, which was further analyzed using content analysis techniques described above in the section on in-depth interviews.

\section{Results}

In-depth Interviews Results: The in-depth interview findings revealed several factors influencing youth health risk behaviors, such as social surrounding including peers and family, aggressive marketing from tobacco and alcohol companies, personal and psychological characteristics, cultural values, and overall situational factors happening in transitional economies of Central Asia. Following Wymer [19], who emphasizes the importance of developing more effective health promotion strategies especially improving the outcomes by identifying upstream causes of social problems and finding ways to reduce their harmful effects, the findings of the current research described below suggest a solid base for understanding the causes of social problems.

Values and uncertainty. The analysis of the in-depth interviews with experts from medicine and education, revealed that the underlying reason for youth uptaking health risks, including addictive behaviors, was uncertainty. As one expert from education area explained "any socioeconomical transition lead to increase in risky and addictive behaviors... new generation is growing in complete uncertainty... especially compared to the older generation grown in absolutely structured Soviet society". Another expert from the area of medicine and public health added that after the collapse of Soviet Union "people lost morale, values, faith...starting from 1992, there has been a sharp increase in suicide attempts and completed suicides". Respondents noted that the old "communist ideology' was lost while new values were not created or adapted as "some countries have religious ideology, some political ideology, but both do not work here". As a result of confusing values and high uncertainty many people and especially teenagers want to "escape from the reality... smoking, drinking, drugs, Internet, computer games". In addition, the situational factors in the country are augmented by personal and psychological factors specific for teenage and youth period.

Youth behavior. Respondents emphasized that health communication is important to the segment of adolescents and young adults, as they are most "vulnerable groups, especially kids from incomplete families, or families with problems... children can be aware of the consequences of risk and addictive behaviors, but still perform this way". The experts mentioned the protest or rebellious behavior of teenagers as a reason why adolescents do what they were told not to do by adults. Furthermore, the tendency to uptake risk and addictive behavior is moderated by the increased deviations in psychological characteristics of adolescents. The expert in addictive behavior from the Center for Psychiatry, Psychology and Narcology commented that "alcoholism or drug addictions are not inherited by children from their parents, but borderline mental disorders such as susceptibility to depression, panic attacks, and deviant behavior...if those borderline mental disorders are not detected and treated in childhood, we have 100\% adult addict". The expert added that these "specific mental disorders" usually come during pubertal period characterized by hormonal and psychological crises. Thus, respondents indicated that public health communications should not only address the observed risk behavior, but influence the causes of the problems.

Consequences. The importance of public health communications to change health risk and addictive behaviors was related by respondents to the severe consequences of those behaviors to individuals and to the society as a whole. The expert from the Center for Psychiatry, Psychology and Narcology pointed out that the most severe consequences to the individuals' health come for the use of drugs. He reported cases of imbecility or dementia happened to adult patients who had diplomas with distinctions but were not able to sum up two digit numbers, "only low level basic instincts left, such as intravital necessities... they had short memory amnesia and atrophy of cortex". This expert added that toxic mania poisons brain and "there is information that many terrorism attacks are conducted by people who used JWH (cannabis substitute), thus they are susceptible to the hypnosis, have hallucinations, strong addiction, abstention, wickedly aggressive dystrophic conditions". Participants noted the health consequences for individuals in the short term and long term and overall negative consequences for the society as weakening the gene pool of the nation. The expert in education said that "Kazakhstan has the highest rate of suicide, thus it has already been influencing our gene pool... there will be a big impact not only for the future of our country, but for all countries". Respondents mentioned the long term effects on the labor productivity with increased level of diseases due to substance use. Another major area brought to the discussion was social impacts such as inability to communicate, build and maintain relationship, and family issues. In addition to health and social risks, participants noted the risks that addicted people can commit crime and be involved in terrorism activities. Along with direct risks, interviewees draw attention to the financial issues, as one participant said "it is the problem of the whole society, related to the all elements of the society... expenses for medical treatment of addicted people, expenses to liquidate the consequences, expenses to have juridical institutions". 
Focus Groups Results: The data analysis of in-depth interviews revealed that smoking and other addictive behaviors are major health risks for adolescents and young adults. Thus, preventing and reducing addictive behaviors, including substance use, among youth is of high importance to the society. The analysis of two focus group interview data generated the following findings. Most of participants agreed that health to the large extent is determined by genes and uncontrollable environmental factors such as polluted air, water, and soil, genetically modified products, work-related stress, etc. However they also believe that individual characteristics and behaviors impact health. Participants discussed harmful and risk behaviors along with their negative consequences. The list of health risk consisted mostly of unhealthy diet, lack of physical activities, and a wide variety of not only harmful and health risk but also addictive behaviors including consumption of substances such as drugs, alcohol, tobacco, other less harmful substances such as chocolate, coffee, fast food, coke drinks, digital activities such as gaming, social networks, watching television, and other behaviors including extreme sports, shopping, weight control, attending night clubs. For every type of health risk behavior respondents were asked to describe the harms and negative consequences. However, in most of the cases the discussion of the risks was too general. Participants used phrases like "it is bad for my health", "I can get addicted to it", "it is not good". Respondents lacked specific knowledge about health risks and consequences for personal health. Moreover, participants were not able to articulate well the extended in time health outcomes and the long term consequences for the society and economy.

Focus group participants brought to the discussion the role of governmental controls and interventions. Taxes were mentioned to reduce the consumption of alcohol and tobacco. Fines for over speeding, not using seat belts and road accidents were listed as a way to promote safe driving. To reduce gaming and social network addictions, participants recommended control and restrictions over the Internet traffic and price discrimination for night time - "the traffic is less expensive at night, kids play during the night; it must be visa versa". Respondents in one focus group discussed the issues of leisure time stating that "kids have nothing to do after school", "most of sport and recreation facilities are too expensive for an average person, moreover the selection of activities is low", "parents are at work all day long and kids are on their own". Another issues related to parents was discussed in the second focus group. Participants stated the role of the family, parents, and siblings in influencing adolescents' behavior proposing that social marketing should be targeted to change behavior of adults who raise children. Another discussion was related to the peer influence. As one respondent said "have good friends with good habits to be on the safe side, stay away from the bad guys".

\section{Discussion}

The results of both in-depth interviews with experts and focus groups with youth pointed out negative consequences of health risk behaviors including addictive behaviors such as smoking, alcohol, drugs, gaming. Obviously, participants of the in-depth interviews, especially from the areas of public health and education, were more specific in describing various negative outcomes for mental and body health, including very severe consequences such as memory amnesia and imbecility in comparison with the focus group members who were more general in their perceptions of health risk using broad terms like "it is bad for the health". Thus, it can be suggested that youth are not well informed about particular health risks, confirming the results of the past research that there is less acknowledgement that smoking could result in a disability significantly affecting the quality of life [20] or findings of other studies about youth underestimating the risks of addictive behaviors and chances that the risks would occur to them [21]. Youth have relative freedom from parents and make their own choices regarding risk behaviors. Young people do not appreciate the risk from smoking, alcohol, and even drugs as they believe that they can quit any time. For example, smokers have biases in processing tobacco related information [22]. Another study of tobacco related attitudes and behavior has found that for children and young adults decision to smoke may be affected by imperfect information [23]. Thus, having the discrepancy in perceptions of outcomes from health risk behaviors between youth and experts and results of past research indicating that youth have imperfect information and often overoptimistic about risks, the recommendation could be drawn that public health communications should contain information about negative consequences of risk behaviors.

As sustained and expanded efforts to promote public health in Central Asian countries are vital to bringing best international health standards, health promotion can lead to a better quality of management as compared to traditional preventive activities by customizing the campaign more specifically to the target market needs and motives, presenting risks more convincingly, and evaluating the campaign and its effects on a continuous base [24]. The matrix approach outlined in the studies of Rothschild [25] and Maibach [26] suggests a continuum of options to pursue behavior change with educational campaigns on the one end of the continuum, targeted at people who are prone to adopt a recommended behavior because of their self-interest and willingness, and legal requirements and judicial penalties on the other end, targeted to change the behavior of people who are resistant to the recommended behavior as they do not perceive it in their selfinterest, social marketing takes the middle ground, where the market is ambivalent in regard to the social change message, and has not identified yet how the proposed behaviors can actually be of benefit to their self-interest. Thus, a consumer research would help to identify attitudes to change among target populations in order to develop the best combination of social change mechanisms. In addition to education and law enforcement, social marketing is to be integrated with other governmental policies and developments.

\section{Conclusions}

The current study revealed that youth is generally aware of the bad consequences of the health risks, but have a poor understanding of the seriousness and specifics of the health risk. Although the health experts have a very good understanding of risks, the youth has "imperfect information" about these risks. Based on the findings of this study, the following initiatives are recommended to reduce health risk behavior among youth in Central Asia:

a) Early and continuous education and provision of comprehensive information about causes, consequences, costs, and alternatives of problem behaviors at all touch points including schools, universities, medical, sport, and health organizations, mass media, social media, and networks.

b) Early medical screening and treatment of adolescents. Provision of affordable professional medical and psychological assistance including deviant behaviors, health risk and substance use behaviors.

c) Development of the infrastructure and facilities for affordable and accessible leisure and recreation activities, including sport, physical exercise, arts, music, interest clubs, and others. Development and leadership of youth networks.

d) Development and enforcement of more strict controls and regulations in regard to sales, marketing, and consumption of 'harmful' products.

e) Marketing research, segmented and targeted health communications, proper message and media decisions to improve the effectiveness of social marketing interventions for public health.

This study contributes to the existing body of research in multiple areas of public health and specifically in the context of the developing economies of Central Asia. The limitations of the study include sampling and data collection. For the qualitative in-depth interviews, there were difficulties in recruiting participants. Despite using maximum variation and critical case sampling technique to select the participants, the final sample was suboptimal. The future research could explore in more details health risk behavior and other public health areas. Quantitative methods could provide additional insights as for the development of the effective health interventions.

\section{References}

[1] Ulikpan, A., T. Mirzoev, E. Jimenez, A. Malik and P. S. Hill. 2014. Central Asian Post-Soviet health systems in transition: has different aid engagement produced different outcomes? Global Health Action, 7, 10.3402/gha.v7.24978.

[2] WHO. 2014. World Health Organization Noncommunicable diseases country profiles 2014. Retrieved on May 21, 2018 from http://www.who.int/nmh/countries/kaz_en.pdf?ua=1

[3] WHO. 2016. World health statistics 2016: monitoring health for the SDGs, sustainable development goals. Retrieved on May 14, 2018 from http://www.who.int/gho/publications/world_health_statistics/2016/en/

[4] Churchill, G. A., and Moschis, G. P. 1979. Television and interpersonal influences on adolescent consumer learning. Journal of Consumer Research, 6: 2335.

[5] Cook, A. 2013. Public health and geological processes: an overview of a fundamental relationship. In O. Salinas (Ed.), Essentials of Medical Geology (2nd ed.). Springer-Verlag. 
[6] World Health Ranking. (2016). Health profile: Kazakhstan. Retrieved on May 21, 2018 from http://www.worldlifeexpectancy.com/country-healthprofile/kazakhstan

[7] Spiegelhalter, D. 2016. How old are you, really? Communicating chronic risk through "effective age" of your body and organs. BMC Medical Informatics and Decision Making, 16, 104. http://doi.org/10.1186/s12911-016-0342-z

[8] USDHHS. 2012. Preventing Tobacco Use Among Youth and Young Adults: A Report of the Surgeon General. Atlanta, GA: U.S.

[9] Carslake, D., Jeffreys, M., and Davey Smith, G. 2016. Being overweight in early adulthood is associated with increased mortality in middle age. Scientific Reports, 6, 36046. http://doi.org/10.1038/srep36046

[10] Muller, D. C., Murphy, N., Johansson, M., Ferrari, P., Tsilidis, K. K., Boutron-Ruault, M.-C., Brennan, P. (2016). Modifiable causes of premature death in middle-age in Western Europe: results from the EPIC cohort study. BMC Medicine, 14, 87. http://doi.org/10.1186/s12916-016-0630-6

[11] WHO. 2008. Report on the Global Tobacco Epidemic - The MPOWER package. Retrieved April 14, 2018 from http://www.who.int/tobacco/mpower/en/

[12] Murray, C.J.L., and Lopez, A.D. 1996. The Global Burden of Disease and Injury Series, The Global Burden of Disease, A Comprehensive Assessment of Mortality and Disability from Diseases, Injuries, and Risk Factors in 1990 and Projected to 2020. Cambridge, MA: Harvard University Press.

[13] Peto, R., Chen, Z.M., and Boreham, J. 1999. Tobacco - The growing epidemic. National Medicine, 5: 15-17.

[14] Gilmore, A., Pomerleau, J., McKee, M., Rose, R., Haerpfer, C., Rotman, D., and Tumanov, S. 2004. Prevalence of smoking in eight countries of the former Soviet Union: results from the Living Conditions, Lifestyles and Health Study. American Journal of Public Health, 94(12): 2177-87.

[15] Rossman, G.B., and Rallis, S.F. 1998. Learning in the Field: An Introduction to Qualitative Research. Thousand Oaks, CA: Sage Publication, Inc.

[16] Moustakas, C. 1994. Phenomenological Research Methods. Thousand Oaks, CA: Sage Publications, Inc.

[17] Creswell, J.W. 2007. Qualitative inquiry \& research design: Choosing among five approaches (2nd ed.). Thousand Oaks, CA: Sage Publication, Inc.

[18] Onwuegbuzie, A. J., and Collins, K. M. T. 2007. A typology of mixed methods sampling designs in social science research. The Qualitative Report, 12(2): 281-316.

[19] Wymer, W. 2011. Developing more effective social marketing strategies. Journal of Social Marketing, 1(1): $17-31$.

[20] Oncken, C., McKee, S., Krishnan-Sarin, S., O'Malley, S.,and Mazure, C.M. 2005. Knowledge and perceived risk of smoking-related conditions: a survey of cigarette smokers. Preventive Medicine, 40(6): 779-84.

[21] Reppucci, J. D., Reven, T. A., Aber, M., and Reppucci, D. 1991. Unrealistic optimism among adolescent smokers and nonsmokers, The Journal of Primary Prevention, 11(3): 227-236.

[22] Chassin, L., Presson, C. C., Sherman, S. J., and Edwards, D.A. 1990. The Natural history of cigarette smoking in adolescents: Predicting young-adult smoking outcomes from adolescent smoking patterns. Heath Psychology, 9(6): 701-716.

[23] Hu, T. W., Sung, H. Y., \& Keeler, T.E. 1995. Reducing cigarette consumption in California: tobacco taxes vs an anti-smoking media campaign. American Journal of Public Health, 85(9), 1218-1222. doi: 10.2105/AJPH.85.9.1218

[24] Loss, J. and Nagel, E. 2010. Social marketing--seduction with the aim of healthy behavior? Gesundheitswesen, 72(1): 54-62.

[25] Rothschild, M. 1999. Carrots, sticks, and promises: a conceptual framework for the management of public health and social issue behaviors. Journal of Marketing, 63: 24-37.

[26] Maibach, E.W. 2003. Recreating communities to support active living: A new role for social marketing. American Journal of Health Promotion, 18(1): 114119. 